\title{
Experimental Study of Acquired Resistance of the Rabbit's Renal Epithelium to Mercuric Chloride
}

By Warrtin C. Hunter, M.A., M.D., Portland, Oregon.

Reprinted from AnNals of INTERNaL Mbpicní, Vol. II, No. 8, February, 1929 pages $796-806$ 


\section{Experimental Study of Acquired Resistance of the Rabbit's Renal Epithelium to Mercuric Chloride ${ }^{*}$}

By Warren C. Hunter, M.A., M.D., Portland, Oregon

T $N$ a previous paper I (I) have shown that a hioh degree of resistance to the injurious effects of uranium in the kidney can be experimentally produced. In a considerable number of rabbits it was found that 54 to 96 times the quantity of poison known to kill original renal tubular cells was insufficient to damage the regenerated epithelitum in the same location. After administration of even the largest doses of uranium the metal was still excreted by the kidney and this together with the lack of histologic evidence of cell injury was considered to be proof of an acquired resistance on the part of the new epithelium. In the previous study the literature on experimental chronic nephritis and that portion of the experimental work of Gil y Gil (2) concerned with acquired immunity of the kidney for uranium nitrate has been reviewed in detail and need not be repeated here. It is sufficient to state that, as with uranium nitrate, Gil y Gil is the only previous investigator who has attempted to induce in the kidney an immunity for mercuric chloride. On this account it is fitting that his work be fully considered before proceeding to a discussion of my own.

\section{Crittcal Review}

Gil y Gil states that the lethal dose of mercuric chloride for rabbits may be determined from the experimental results of Suzuki (3), Barbour (4) and Nakata (5). He says: "Der erste (Suzuki) dieser Autoren stellte fest, das bei Injektion von $0.003 \mathrm{~g}$. Sublimat bei einem Kaninchen von $700 \mathrm{~g}$ Gewicht nach 36 Stunden der Tod eintritt. Ein anderes Kaninchen von I700 $\mathrm{g}$ Gewitcht, welches von Suzuki mit $0.005 \mathrm{~g}$ Sublimat auch subkutan injiziert wurde, ging nach 3 Tagen zugrunde. Der zweite Autor (Barbour) bezeichnete die tődliche Dosis mit 0.004 g Sublimat subkutan per Kilogramm Körpergewicht des Versuchstieres.

Auf Grund dieser Resultate bezeichnen wir für $2 \mathrm{~kg}$ Kổrpergewicht eines Kaninchens die mittleren der beiden (0.003 und $0.004 \mathrm{~g})$ Dosen gleich $0.0035 \mathrm{~g}$ Sublimat subkutan injiziert als tődliche Dosis." (p. 642)

Reference to these publications shows little basis for such assertions.

*Fellow in Medicine, National Research Council.

tFrom the Pathological Laboratory, Uni-
Two animals constitute too small a In most instances the dosage in rabbits series on which to base definite con- was considerably greater than 0.0035 clusions regarding the lethal dose of a gm. per kilogram of body weight. poison. Furthermore Gil y Gil overlooked an important complicating factor. The smaller rabbit had intra venously 5 cubic centimeters of carmine and the larger animal 7 cubic centimeters of the dye after the sublimate injection. Suzuki's protocol show that the former died shortly after the carmine injection and that the latter became so weak within four hours that it was killed. The relatively sudden exitus strongly suggests an embolic death. In my experience the injection of such quantities of carmine has more than once been the cause of death in poisoned rabbits. Forbu (6) has likewise found that rabbit are invariably killed by large injection of carmine. Granting that Suzuki may have been more fortunate than other in this respect the fact remains that complicating factor was introduced and one cannot be certain whethe death was caused by the mercury or the dye.

Barbour's sole purpose was to test the efficacy of an antidote for mercuric chloride. Furthermore he introduced the poison intravenously instead of subcutaneously and the doses were based on I kilogram body weigh rather than 2 kilos as given in the passage quoted.

Nakata's study was primarily concerned with the pathologic stages of the sublimate kidney in the human. For the purpose of comparison rabbits were given sublimate in quantities corresponding according to body weight with that taken by the human cases.
Gil y Gil did not himself study the pathologic changes in the acute sublimate kidney but quotes the deccriptions of Suzuki who found in two rabbits after subcutaneous administration of 0.003 and $0.006 \mathrm{gm}$ of sublimate a well marked necrosis of epithelium in the distal and transitional segments of the proximal convoluted tubules. He emphasizes that the amounts capable of producing such damage were administered subcutaneously and that he has given much larger doses intravenously to nearly all rabbits in his series.

The conclusion that renal immunity to mercuric chloride may be experimentally demonstrated is based on the study of nine rabbits. No definite plan of experimental procedure was followed with the exception of time intervals between injections. The irregular manner in which all animals were given both subcutaneous and intravenous injections renders difficult any reliable interpretation of results. Further important information may be gained from the discussion of the microscopic findings in each animal:

Rabbit I. Necrosis of all except first part of proximal convoluted tubular epithelium; no increase in connective tissue. The author rightfully does not claim that inmmunity was shown in this case.

Rabbit 2. No demonstrable changes in any tubular cells; hyperemia of glomeruli; glomerular epithelium uninjured. Gil y Gil seeks to explain the marked difference in the kidney of 
this animal and the first on the ground imal convoluted tubules at the juncthat Rabbit I received more sublimate tion of cortex and medulla. In this in the first two injections than did the case also Gil y Gil overlooked the very second animal. That Rabbit 2 subse- important factor of time. The last quently had a greater amount of pois- sublimate was administered fifty-two on intravenously without exhibiting days before death and it is highly kidney lesions led to the conclusion probable that all of the poison would that it was immunized by the first in- be excreted long before this time. A jection since the quantity given was poison cannot be assumed to act insufficient to produce definite changes definitely and if cell injury is taken in a non-immunized kidney. Here Gil as a criterion of lack of immunity the y Gil has quite overlooked such fac- examination must be made when the tors as individual differences in sus- injury is at its height.

ceptibility, variation in absorption of the poison and the fact that the kidney of Rabbit 2 was not examined until twenty days after the last injection, while in the first animal the kidneys were studied two days after the final administration of sublimate. In Rabbit 2 there is no mention of epithelia regeneration yet the animal was considered to be immunized. Again, as in the uranium series, the author fails to state what epithelium becomes resistant. After quoting Menten ( 7 ) to the effect that exceedingly small doses of sublimate will produce definite histological alterations in kidney cells within five minutes after injection Gil y Gil allowed twenty days to elapse following an intravenous injection, after which according to his own statement there is rapid and extensive damage, and then considers the kidney immunized.

Rabbit 3. Atrophy of both glomeruli and tubuli in outer zone of cortex; proximal convoluted tubular epithelium well preserved except in some of the third segments where there is obvious necrosis; abundant connective tissue in transitional parts of the prox-
Rabbit 4. Discussion is unnecessary in this instance since the author does not assert that immunity was produced.

Rabbit 5. Atrophy of cortex with great diminution of epithelium in proximal convoluted tubules which are lined by endothelial-like cells. Most transitional segments of these tubules are difficult to distinguish but appear to have flattened epithelial linings. Evidently Gil y Gil considered this animal immune because of its ability to excrete within three hours about onethird of the last dose of sublimate The fifteen day interval between the final injection and death is certainly too great for any microscopic evidence of immunity to be of value.

Rabbit 6. Glomeruli unchanged. All tubules intact except the distal divisions of the proximal convoluted tubules where there is cellular regeneration and only slight evidence of inury. Immunity is not mentioned. The protocol shows that the animal lived tion and this alone is sufficient to exclude it on the ground that ample seventeen days after the last injec- time was allowed for complete cellular regeneration.

Rabbit 7. Fresh degenerative changes in the epithelium generally. The quantitative estimation of mercury excreted after the last injection of $0.0 \mathrm{gm}$. gave $0.005 \mathrm{gm}$. and for this reason the kidney was believed to be immunized. This in spite of the microscopic evidence of widespread cellular scopic e
damage.

Rabbit 8. First and second divisions of proximal convoluted tubules uninjured, some necrosis in distal division. Following the final injection of 0.05 $\mathrm{gm}$. between 0.0042 and $0.0045 \mathrm{gm}$. was excreted in the urine during the first three hours and the kidney was therefore believed to be immune. When we remember that the selective action of mercury is in the segments of the proximal convoluted tubules, in which the author has described necrosis, it is difficult to believe that any immunity was shown in this instance.

Rabbit 9. No claim is made for immunity.

The author does not state whether or not the intestine was examined in any of the animals. The stain for hyaline droplet degeneration was done in but one instance and was negative.

In order to compare the excretory ability of the kidney in non-immunized and immunized sublimate animals a normal rabbit was given $0.005 \mathrm{gm}$. of mercuric chloride subcutaneously and the urine collected by catheter for eight hours. In the first four hours there was no excretion while in the second period o.ooI $\mathrm{gm}$. was excreted. From this the author concludes that in non-immunized animal the rate and quantity of excretion is appreciably decreased. However if we compare this result with those obtained in the so-called immune animals it will be found that: Rabbit 5 given o.oI $\mathrm{gm}$. intravenously excreted about one-third of this amount in three hours; Rabbit 7 , with o.0I gm. subcutaneously excreted one-half the dose, but not until twenty-four hours had elapsed, while in Rabbit 8 which had received $0.05 \mathrm{gm}$. subcutaneously excreted only about one-eleventh of this amount within three hours. Comparative results are of value only when the dosage and time have been identical.

In summary Gil y Gil states that the experimental results with sublimate corroborate those obtained with uranium. With sublimate it was also possible to build up a remarkable resistance of the tubular apparatus by reason of which the poisons will be, in contrast to non-immunized animals, excreted more rapidly and in greater quantities.

It is obvious that not a single case is convincing and above criticism. In the few instances where immunity was possible the results are questionable on account of the long periods of time elapsing between the last administration of sublimate and the examination of the kidney. The quantatative analyses are of little value as proof of immunity for reasons pointed out above.

\section{AUT'HOR'S EXPERIMENTS}

In view of Gil y Gil's failure to determine the lethal dose of sublimate and his error in its computation from the work of others it was deemed necessary to establish this point before 
proceeding with the immunization experiments.

I. Subcutaneous Letithal Dose

Rabbits of equal weight were grouped in pairs and to each pair the same quantity of poison was administered. The dosage per kilogram of body weight varied from $0.002 \mathrm{gm}$. to 0.02 gm. Of the fourteen animals receiving from 0.002 to $0.005 \mathrm{gm}$. per kilo four died (28.5 per cent). These occurred as follows : $0.002 \mathrm{gm}$. one (I7 days), $0.003 \mathrm{gm}$., two ( 7 and 8 days), $0.005 \mathrm{gm}$. one (9 days). The percentage of mortality is not great enough to consider any of these amounts the minimum lethal dose. All of the eight rabbits receiving from 0.006 to $0.012 \mathrm{gm}$. per kilo survived. Two animals given $0.015 \mathrm{gm}$. per kilo and one having $0.02 \mathrm{gm}$. on the same basis died within 2 I-2 to 4 days. The first figure corresponds very closely to that of Lyon (8) who found that o.or64 $\mathrm{gm}$. per kilo usually proved fatal within twenty-four hours. On the basis of these results $0.015 \mathrm{gm}$. per kilo has been taken as the subcutaneous minimum lethal dose of mercuric chloride for rabbits.

2. Intravenous Lethal Dose

The same general plan of the subcutaneous group was followed. Seven animals received o.oor gm. per kilo; six survived, one died after I7 days. Two rabbits had $0.002 \mathrm{gm}$. per kilo gram; one died within 3 days, the other survived. Both animals given $0.003 \mathrm{gm}$. per kilo succumbed, one after 15 hours, the other in 9 days. So far as is permissible to draw conclu- sions from the limited number of these experiments $0.003 \mathrm{gm}$. per kilo intra venously seems to be the minimum amount that will kill all animals. It will be noted that this is exactly onefifth the subcutaneous lethal dose.

\section{IMMUNIZATION EXPERTMENTS}

\section{Material and methods}

Rabbits were used exclusively. The strength of mercuric chloride solution employed was at first 0.001 or 0.002 gm. per cubic centimeter of distilled water. As the dosage was increased the concentration was raised to o.o gm. per cc. in order to avoid the injection of such large quantities of fluid as would have been required had the weaker solutions been used.

The subcutaneous immunization series consisted of two groups of three animals each; in one the initial dose was $0.002 \mathrm{gm}$. per kilo, in the other $0.003 \mathrm{gm}$. Five rabbits had intravenous injections exclusively, the initial dose of $0.00 \mathrm{r} \mathrm{gm}$. per kilo being doubled thereafter. In addition nine animals which had been given sublimate subcutaneously to determine the lethal dose but which failed to succumb were afterward given one or more intravenous administrations.

Intravital staining with carmine, to determine the localization of the sublimate lesions in the tubules, was carried out in one acute and one chronic sublimate animal.

The acute mercuric chloride kidney

In none of the kidneys of animals dying from the effects of small subcutaneous doses of mercuric chloride was there any appreciable necrosis of tubular epithelium. Three were studied, seven, nine and seventeen days respectively, after administration of the poison. All showed high grade parenchymatous degeneration of the tubular epithelium but little actual ne crosis. In the glomeruli aside from slight swelling and sometimes desquamation of epithelium covering the tufts nothing was observed except congestion of the vessels.

With higher dosages (0.015-0.02 gm.) definite necrosis of cells in the distal and transitional segments of the proximal convoluted tubules occurred. The affected segments are found here and there in all zones of the cortex with many still escaping injury. At this stage (2 I-2 to 4 days) practically all cells in the divisions affected by the sublimate are dead, for the most part desquamated, and forming loose casts at the site of injury and in the upper part of the descending limb of Henle. The few nuclei still present are markedly pyknotic. A distinct difference is noted in the appear ance of some of the dead cells in the mercury kidney from that seen in the uranium organ in that their morphology is fairly well preserved and the cytoplasm has a distinctly hyaline ap pearance. Most cells however break up into finely granular debris. Fat in the necrotic cells is less constant than in uranium nephritis. The epithelium of the first and second divisions of the proximal convoluted tubules shows parenchymatous degeneration. The glomerular vessels are moderately congested; no apparent change is visible in the epithelium of Bowman's capsule, but not infrequently the covering epithelium of the tufts desquamates.
In the capsular space some albumin is often present but blood is rarely seen. Cystic intraglomerular hemorrhages, so common in the acute uranium kidney, occurred in only three of the thirty six cases studied. Two of the three animals had received large intravenous injections of sublimate. Hyaline droplet degeneration, also common in the uranium kidney, was rarely observed in the acute stages although in one animal having 2 milligrams of mercuric chloride intravenously these bodies were fully as abundant as in any acute uranium kidney. All others were negative. In the tubular epithelium this form of degeneration was noted in five instances where death occurred in the acute stage of poisoning. Calcification of casts was observed in three of twelve rabbits dying from the effects of the first injection, the earliest appearance being the fourth day.

Regeneration of epithelium

This begins rather constantly on the fourth day. The new cells are in all respects similar in appearance to those found in the uranium kidney, namely, elongated flattened cells with hyperchromatic nuclei and bluish-pink staining cytoplasm. One important difference is however not uncommon; in the uranium kidney most of the dead cells quickly break up and form granular masses which are soon swept out of the tubules but in the sublimate kidney, not a few cells undergo a hyaline change and remain in the lumen of the affected segments. Often such cells are still present when regeneration begins and the protoplasm of the new cells quickly pushes between the dead 
masses and within a short time com- poison than that known to be capable pletely envelopes them. Heineke (9) of destroying the original cells, was human kidney has described in much minutes after injection or living long detail the apparent phagocytosis of enough after the final dose for regendead cells by regenerating epithelium. eration to take place are included. The His excellent plates show exactly the number of animals meeting these resame process I have frequently ob- quirements is very small. served in rabbits. The fate of the new epithelium in such a location is of interest. When the number of dead cells enveloped by new epithelium is not large the tubule may again become patent but when the number is so great as to fill the lumen and these become surrounded by regenerated cells the entire mass may calcify. As the regenerated epithelium in the sublimate kidney grows older it not infrequently becomes somewhat cuboidal but never regains the normal shape and, as in the uranium kidney, always stains darker than the original epithelium and is easily recognized.

\section{ImMUNization with Sublimate}

-General Considerations

For reasons already pointed out in the critical review it was not deemed advisable to duplicate exactly the experimental procedure of Gil y Gil. Instead the general plan by which good results were obtained in the uranium series was followed, i.e., adherence to one mode of administration, allowing sufficient time for epithelial regeneration and as complete a recovery of the animals as possible after each injection. Likewise the same criterion of cellular resistance discussed in detail in my previous paper (I), lack of injury to regenerated epithelium after administration of larger quantities of
It is difficult to conceive of a nephrotoxic substance less well suited for the demonstration of local cellular immunty than mercuric chloride. First, there is almost invariably a marked local inflammation and necrosis of tissue at the site of subcutaneous injections. This must mean that some of the poison is not absorbed and is a very undesirable actor when the full effect is wanted in the kidney. Second, intravenous injection of even moderate sized doses is dangerous. A number of animals in he writer's series died from thrombosis of the right ventricle almost immediately after the larger intravenous injections. In these animals the time which the sublimate could have acted on the kidney was so short that no definite fresh epithelial damage could e made out and for this reason it was necessary to exclude several animals from the immune series. Third, any ppreciable quantity of mercuric chlorde, whether administered subcutaneously or intravenously, produces in rabbits a marked diphtheritic enterocolitis, so severe that clinically the animals seemed to suffer as much from the intestinal lesions as the nephritis Furthermore an enterocolitis indicates hat the metal is excreted through the bowel as well as the kidney and one cannot be certain how much has reach the latter. Fourth, absorption of sublimate after subcutaneous admin-

istration may be very slight if the degree of kidney damage is a reliable criterion. This is particularly well illustrated by one of the rabbits in the writer's series. The animal received $0.004,0.008,0.016$, and $0.032 \mathrm{gm}$. of sublimate over a period of 63 days and was killed 3 days after the last injection. Examination of the kidney revealed only a few tubules with regenerated epithelium; for the most part there wâs only well marked parenchymatous degeneration and but little actual necrosis. The marked local reaction at the sites of injection and the extensive intestinal lesions found at autopsy in this rabbit were much more severe than those in the kidney. In contrast to this and indicating further the variability in absorption of sublimate may be mentioned the finding of a definite chronic nephritis in another rabbit of the same group which had almost the same quantity of sublimate.

The numerous and serious objections to sublimate just cited makes it impossible to speak with certainty of an acquired immunity of renal cells for this substance. The findings in a few animals in which immunity is possible may now be discussed.$$
\text { RABBTT 2. } 0.002-S
$$

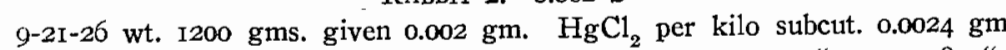

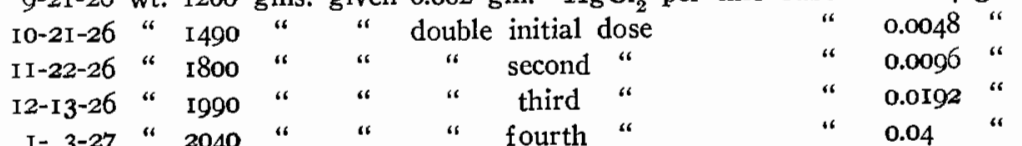

Kidneys: combined weight $20 \mathrm{gms}$. The ing cortical surfaces which are in general pale but show also moderate numbers of petechio. The surfaces are smooth in laces, finely granular in others. On sectoning con grante resistance is encounter but there is no gross evidence of lime salt deposition is junstion. The cortex is pale and at the carring.

Microscopic

Zenker-formalin fixation, hemotoxylin and eosin stain. When the number of proximal convoluted tubules showing recent necrosis of epithelium are compared with the same tubules lined by regenerated cells it is apperent that more damere has resulted from the last dose than all previous ones comhined. The luming of the segments last damaged are packed with desquanted necrotic gun gun. Casts are very nille f the tubus con and collocting ducts. None of the casts contain lime salts. In the cortical zone nearest the medulla many of the tubules are lined by regenerated epithelium but this is true to a much lesser extent in the intermediate and outer zones of the cortex. The new cells are flattened or irregular in outline with dark bluish-pink staining cytoplasm and hyperchromatic nuclei and often forming giant cells or conin the cytoplasm the remains of tein in the dead epithelum. In some instances the la

04 days.

\section{Died 3 days after last injection. Total I07 days.}

AUTOPSY Wed cells show no evidence of injury. Sec-

- tions stained for fat with Scharlach-R disthorax Marked diphtheritic colitis. close a considerable fatty content in casts 
and some desquamated cells. Some of the ior a few small dark depressions. No cells of the proximal convoluted tubules re- difficulty encountered in sectioning, no evitaining the original epithelium give the dence of calcification. The cortex is pale staining reaction for hyaline droplet degen- the markings are obscured, no fresh neeration.

Glomeruli: Most of these structures exhibit little change except slight loss of epithelium over the loops and more rarely Bowman's mer the lops and more rarely varies greatly. In all sections theod content varies greatly. In all sections there may been partilly destrey glomeruli which have been partially destroyed by intraglomerular hemorrhages having the exact appearance of those frequently observed in the acute uranium kidney. The petechiæ seen grossily on the cortical surface are no doubt the rather numerous pure blood casts in the tubules. Hyaline droplet degeneration is fully as pronounced in the glomerular capillary walls, as in any acute uranium kichey. Rarely there is slight proliferation of Bowman's epithelium and still more rarely small epithelial crescents. In this case the olomeruli certainly cannot be regarded as im mune but on the contrary are more dan inmune but on

Van Gieson's preparations disclose a very slight increase of connective tissue about the regenerated tubules. In the interstitial tissue are moderate numbers of lymphocytes and plasma cells.

Liver:-slight fatty degenerative infiltration of cells about central veins.

$$
\text { Rabiti 2. Sub. II }
$$

ro-16-26 wt. $1600 \mathrm{gm}$. given $0.003 \mathrm{gm}$. $\mathrm{HgCl}_{2}$ per kilo subcut. $0.005 \mathrm{gm}$.

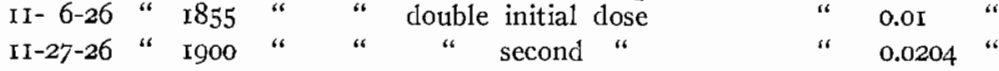

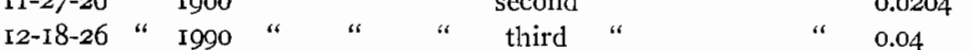

63 days.

Killed 3 days after last injection. Total 66 days.

AU'IOPSY

Weight 1765 gms. Ulceration at site of third injection and edema at site of last administration. No ascites or hydrothorax. Bladder contains io cubic centimeters of clear yellow urine. Marked diphtheritic co-

Kidneys :-combined weight 20 gms. Capsules not adherent, surfaces smooth except
The protocols of a few other rabbits might be added but the degree of immunity attained is not great enough to be of any value.

Drscussion of Risults

Because of the retention of a portion of the mercury at the site of in- jection and the excretion by way of last injection, and, although the origithe intestine it was not considered worth while to attempt to estimate the quantity excreted by the kidney. That part of the last dose in each instance reached the kidney is evidenced by fresh necrosis of original but not the regenerated convoluted tubular cells, indicating increased resistance on the part of the latter. The degree of this resistance is unknown. Had all the last mercury given reached the kidney this would be sixteen times the origina dose in the first rabbit and eight times in the second animal, but we know from the intestinal and local lesion that such was not the case.

Tolerance of the whole organism for mercuric chloride is very limited, in most instances being only about twice the subcutaneous lethal dose. This is in marked contrast to the results obtained with uranium for which a tolerance of thirty-two or forty times the lethal dose was frequently attained.

In only one animal in the sublimate series was a truly chronic kidney lesion obtained. The microscopic picture in this instance was very similar to that of a chronic uranium kidney, showing great reduction in the number of original proximal convoluted tubular cells, extensive regeneration, considerable interstitial scarring and pigment deposition in the regenerated cells. The glomerular capsules were thickened, the Bowman's membrane epithelium hyperplastic and forming epithelial crescents and even obliteration of the capsular space. This animal received four intravenous injections, beginning with $0.0018 \mathrm{gm}$. and ending with $0.0144 \mathrm{gm}$. Unfortunately death occurred within a few minutes after the nal epithelium shows parenchymatous degeneration and even early necrosis it was thought advisable to exclude the animal from the immune series because of the short time the poison could have acted. The case is of value, however, to show that sublimate also produces chronic glomerular as well as tubular lesions in spite of the fact that in the acute stage glomerular damage is less constant and less marked than in uranium poisoning. Hyaline droplet degeneration in the glomeruli is not common in either the acute or subacute sublimate kidney, occurring in only seven of the thirtysix animals of the series. In the damaged convoluted tubular epithelium this form of degeneration was observed in twenty-one of the thirty-six kidneys. Fatty degenerative infiltration in living cells and casts was noted in twenty-six instances. In the living cells fat is present in about the same quantity as in the uranium kidney but in less constant and not so abundant in casts.

Fatty degenerative infiltration was observed in the liver only four times, extensive in one, slight in the others. seen in uranium animals is lacking

\section{Conclusions}

I. Local corrosive action and irregularity of absorption after subcutaneous administration, the danger of thrombosis following intravenous injection and the excretion by the intesine resulting in severe enterocolitis, makes sublimate an undesirable substance to use in the experimental proThe constant relationship to dosage 
duction of immunity in renal epithelium.

2. In rabbits the amount of mercuric chloride absorbed varies greatly. In some several injections may be given without producing any marked change in the renal epithelium while in others the same quantity causes well marked chronic glomerulotubular lesions very similar to those produced by uranium.

3. A slight degree of acquired immunity for sublimate can be demon- strated in regenerated epithelium and glomeruli.

4. Glomerular injury, as evidenced by necrosis of epithelium, hemorrhages and hyaline droplet degeneration is less frequent than in the uranium kidney.

5. A constant and striking phenomenon in the sublimate kidney is the envelopment of necrotic cells by regenerating epithelium.

6. In the rabbit calcium deposition in casts is inconstant.

\section{REFERENCES}

(I) Hunter, Warken C.: Experimental Study of Acquired Resistance of the Rabbit's Renal Epithelium to Uranyl Nitrate. Ann. Int. Med., (April) 1928, i :747-789.

(2) GII, y GIL, Carlos.: Die Immunität im Nierenepithelgewebe. Beitr. z. path. Anat., 1924, 1xxii : 621.

(3) Suzukr, Tatzuo: Zur Morphologie der Nierensekretion unter physiologischen und pathologischen Bedingungen. Fischer, Jena, I9I2.

(4) Barbour, H. G.: Mercuric Chloride Poisoning in Animals Treated Unsuccessfully by Parænteral Administration of Hall's New Antidote. J. A. M. A., 1915, lxiv : 736 .

(5) Nakata, T.: Die Stadien der Sublimatniere des Menschen, nach ihren makroskopischen und mikroskopischen Besonderheiten. Beitr. z. path. Anat., 1922, 1xx: 282-310.
(6) Forbus, W. D.: Pathologic changes in Voluntary Muscle. II. Experimental study of degeneration and regeneration of striated muscle with vital stains. Arch. Path. and Lab. Med., 1926, ii : 486.

(7) Menten, M. L.: Pathological Lesions Produced in the Kidney by Small Doses of Mercuric Chloride. J. Med. Research, 1922, xliii: 315 .

(8) Lyon, Grorge: Inflammatory Changes in the Kidney; an Experimental Study of the Action of Some Toxins and Poisons Upon the Kidney and also Upon the Spleen. J. Path. and Bact., I903, iii : 40I-455.

(9) HEINEKE, A.: Die Veränderungen der menschlichen Niere nach Sublimatvergiftung mit besonderer Berücksichtigung der Regeneration des Epithels. Beitr. z. path. Anat., I909, xlv : 197-244. 